\title{
Mentoria durante pandemia: um ambiente de acolhimento, pertencimento e humanização para primeiranistas
}

\section{Mentoring during the pandemic: a welcoming environment of belonging and humanization for first-year students}

\author{
Vanessa dos Santos Silva' (1) | vs.silva@unesp.br \\ Aristides Augusto Palhares Neto' 10 aristides.palhares@unesp.br \\ Rubia de Aguiar Alencar' 1 (1) rubia.alencar@unesp.br \\ Renata Maria Zanardo Romanholi' (1) r.romanholi@unesp.br \\ Maria Cristina Pereira Lima' (1) maria.cristina@unesp.br \\ Jacqueline Costa Teixeira Caramori' (1) j.caramori@unesp.br
}

\begin{abstract}
RESUMO
Introdução: O Programa de Mentoria da FMB foi construído coletivamente durante os anos 2018-2019, com assessoria externa e amplo apoio institucional. O sofrimento psíquico dos alunos de graduação nas áreas da saúde, já descrito na literatura, intensificou-se com a pandemia da Covid-19, fortalecendo a necessidade do programa para os primeiranistas dos cursos de Enfermagem e Medicina.

Relato de experiência: Foram realizadas oficinas para formação do grupo gestor do programa e do grupo de mentores. Em agosto de 2020, após divulgação entre representantes e conselhos, a Oficina de Sensibilização com os primeiranistas teve grande adesão. A construção de um ambiente virtual caloroso, leve e lúdico foi prioridade do grupo, assim os mentores foram apresentados aos alunos, e estes receberam o convite para ingresso ao programa. Os alunos declararam suas preferências por seus mentores em questionário que ficou aberto por duas semanas. Formaram-se grupos foram que se encontraram ao menos mensalmente, para que pudessem construir ambientes de acolhimento e afetividade, e discutir temas de interesse e escolha dos alunos. O grupo gestor se reúne com mentores bimestralmente, de modo a priorizar espaços de trocas e compartilhamento das vivências, dos desafios e das superações, e construir um ambiente colaborativo de aprendizado mútuo. Na Enfermagem, a adesão dos alunos foi de $100 \%$, e na Medicina, de $85 \%$. As avaliações dos alunos sobre o programa foram muito positivas.
\end{abstract}

Discussão: O programa propiciou ambiente de diálogo sobre a saúde física e mental, gestão do tempo e atividades acadêmicas, como iniciação científica e extensão universitária. Mentores, mentorados, grupo gestor e instituição vivenciaram momentos de construção de vínculo afetivo e ambiente colaborativo.

Conclusão: O programa conseguiu ter visibilidade entre alunos, professores e profissionais, e está conseguindo se firmar como estratégia para resgatar a afetividade e humanizar as relações na instituição, num momento de tantas inseguranças, sofrimentos e desafios.

Palavras-chave: Mentoria; Ensino Superior; Estudantes; Covid-19; Acolhimento.

\begin{abstract}
Introduction: The FMB Mentoring Program was built collectively between 2018/19, with external advisory and institutional support. Mental suffering among undergraduate students in the health area is well known, but became more intense with the onset of the Covid-19 pandemic, and programs like mentoring have been especially necessary for first-year students.

Experience Report: Workshops were held to create the program steering group and mentoring team. In August 2021, once the program had been presented to representatives and boards, the Awareness Raising Workshop was conducted with high student participation. The group prioritized the construction of a warm, light-hearted and playful virtual environment, and the mentors were introduced to the students in this vein, who in turn received the invitation to join the program. The students named their preferred mentors in a questionnaire that remained available for two weeks. The groups were formed and met at least once a month in a welcoming and affectionate setting to discuss issues of interest to and chosen by the students. The steering group meets with the mentors every two months, focusing on spaces for exchange and sharing of experiences: challenges faced and overcome, and building a collaborative environment of mutual learning. In Nursing, 100\% of the students joined the program, and in Medicine, $85 \%$. The student assessments of the program were very positive.
\end{abstract}

Discussion: The program provided an environment of dialogue in mental and physical health, time management, and academic activities such as scientific initiation and university extension. Mentors, mentees, the steering group and institutional coordinators experienced moments of caring, collaboration and affection.

Conclusion: The mentoring program attained visibility among students, teachers and professionals and is becoming established as a strategy to retrieve the caring and humanistic aspects of relations in the institution at a time of such uncertainty, suffering and challenges.

Keywords: Mentoring; Higher Education; Students; Covid-19; Welcoming.

${ }^{1}$ Universidade Estadual Paulista, Botucatu, São Paulo, Brasil.

Editora: Patrícia Lacerda Bellodi.

Recebido em 28/02/21; Aceito em 01/04/21.

Avaliado pelo processo de double blind review. 


\section{INTRODUÇÃO}

A aprovação no vestibular para o curso de Medicina ou Enfermagem da Faculdade de Medicina de Botucatu da Universidade Estadual Paulista (FMB-Unesp) é motivo de alegria para o estudante e sua família. Mudanças acontecem e podem ser vivenciadas como positivas ou negativas, a partir da perspectiva individual: saída da casa dos pais ou familiares, novas responsabilidades, mais liberdade, necessidade de financiamento para custeio e lazer, novas demandas de estudo e oportunidades acadêmicas. Essas experiências, somadas ao longo e estressante processo na formação de profissionais da saúde, às reformulações no processo de aprendizado de passivo para ativo, ao volume de informações e matérias a serem estudadas, à diminuição do tempo dedicado ao lazer, à competitividade, ao contato com a morte e as doenças, ao medo de falhar e às dificuldades econômicas, embora sejam oportunidades para o desenvolvimento e maturidade, são comumente relatadas por estudantes de Medicina e Enfermagem como estressoras em diferentes partes do mundo'.

As dificuldades enfrentadas pelos estudantes da área da saúde em geral e o decorrente sofrimento psíquico têm sido objeto de frequentes investigações ${ }^{2}$. Estudos apontam para o crescimento da morbidade psicológica, associado à exposição dos estudantes a várias fontes de estresse nas atividades envolvidas na formação. Contudo, a literatura mostra também que aprender pelo exemplo e com orientações de pessoas que já têm uma formação profissional sólida pode tornar o processo mais dinâmico, promover um resultado mais consistente e ampliar a oferta de fatores protetores para a saúde mental ${ }^{3}$.

A FMB-Unesp já acumulava experiências anteriores de tutoria ou mentoria com maior ou menor envolvimento e sucesso. Em 2018 contou com uma assessoria externa, a partir da submissão de proposta ao Edital n 4/2018 da Pró-Reitoria de Graduação da Unesp - (I)novaGrad, que permitiu dar suporte à proposição de inovações no âmbito institucional. A aprovação da proposta de Capacitação em Mentoria como Suporte para o Profissionalismo e para o Crescimento Pessoal nas Profissões da Saúde ocorreu em setembro de 2018. A construção do programa se deu coletivamente, com participação de aproximadamente 30 professores, profissionais e alunos, com oficinas sensibilizadoras e grupos de trabalho, durante um ano, resultando na elaboração do Programa de Mentoria, cuja missão é oportunizar situações que possibilitem transformação positiva na vida do estudante de Enfermagem e Medicina da FMB-Unesp, acolhendo, ajudando no crescimento e no desenvolvimento, reduzindo estresse e sofrimento. As trocas de experiências entre mentores e mentorados pretendem contribuir para a aprendizagem e o cuidado em saúde, auxiliando o estudante a usufruir do potencial oferecido pela instituição em sua formação pessoal e profissional.

Com o início da pandemia da coronavirus disease 2019 (Covid-19), a necessidade do programa ficou mais clara e urgente ${ }^{4}$, especialmente para os primeiranistas de Enfermagem e Medicina, que, embora tenham sido recebidos pela FMBUnesp e participado da semana de integração, logo na semana seguinte, antes mesmo de conhecerem as instalações, o currículo ou seus professores, já receberam a notícia que as aulas estavam suspensas por tempo indeterminado e voltaram para as suas cidades de origem com sentimentos de indefinição, frustração e medo, passando o primeiro ano praticamente todo em ensino remoto. Alguns nem chegaram a conhecer Botucatu, pois estavam na lista de espera, e sua matrícula foi feita on-line, após ter sido decretada a pandemia.

Logo sepercebeu quea pandemia eo distanciamentosocial não durariam apenas algumas semanas. Esforços institucionais viabilizaram o ensino de forma remota:capacitação de professores, teste em plataformas e discussões com representantes de classe, conselhos de classe e conselhos de cursos. Passados esses primeiros momentos, retomou-se o Programa de Mentoria, o que exigiu alguns procedimentos: buscar mentores, repensar o programa em plataformas virtuais e fortalecer o grupo gestor (Gg), que assumiu o programa como prioridade. Com a presença adicional de uma estagiária e um especializando em Pedagogia, a equipe foi ampliada, e começaram os trabalhos para colocar o programa em efetivo funcionamento.

\section{RELATO DE EXPERIÊNCIA}

\section{Organização do programa: personagens}

Identificaram-se como principais personagens do Programa de Mentoria da FMB-Unesp os mentores, os mentorados e o Gg. Outros setores da FMB que se ocupam de questões discentes também foram envolvidos na etapa de construção do programa: centros acadêmicos e atléticas dos cursos de Enfermagem e Medicina, conselhos de classes e de cursos, Seção Técnica de Graduação, Núcleo de Apoio Pedagógico (NAP), Serviço de Apoio Psicológico ao Estudante (Seapes), Comissão Local de Permanência Estudantil (CLPE), que atuaram como parceiros e facilitadores da proposta, de modo a criar um trabalho em rede.

Na construção coletiva do perfil do mentor, considerouse que sua principal característica é ter interesse pelo aluno com capacidade de construção de vínculo. As competências desejáveis dos mentores no decorrer das atividades e funções da mentoria estão resumidas no Quadro 1. Podem ser mentores todos os profissionais que exerçam atividades acadêmicas com os alunos da FMB-Unesp, o que inclui docentes da FMB e do Instituto de Biociências de Botucatu (IBB), e também servidores técnicos. 
Quadro 1. Competências desejáveis no desempenho da função mentor elaboradas pelos membros da Oficina de Construção do Programa de Mentoria, com a assessoria externa em 2019, Botucatu/SP.

\section{Competências (saber-fazer) do mentor:}

Construção de vínculo é habilidade fundamental, é necessário que o mentor esteja atento e disponível para fomentar a formação de vínculos com seu mentorado. Essa habilidade está relacionada a:

1. Praticar a escuta e a continência (a capacidade de ouvir e acolher) atenta, sem julgamentos, disponível (tempo e espaço) e acolhedora.

2. Reconhecer seus limites e buscar ajuda: o mentor deve perceber quando os problemas apresentados estão além de suas possibilidades de ação e, nesses casos, deve buscar ajuda de outras instâncias institucionais. Compreende-se também como limite lidar com o que é do outro, sem se deixar desorganizar.

3. Demonstrar empatia: o mentor deve buscar a empatia, a capacidade de se colocar na posição do outro, com o intuito de acolher e respeitar, "aceitando" as limitações e mobilizando positivamente sentimentos e afetos para transformações possíveis.

4. Respeitar o outro: respeitar o "tempo" do mentorado e seus processos para o trabalho com o mentor e suas decisões.

5. Perseverança: não desistir nas primeiras dificuldades ou nos primeiros sinais de resistência.

É fundamental que o mentor reconheça a importância do autoconhecimento e da comunicação efetiva, que são essenciais para as habilidades nomeadas.

Fonte: Elaborado pelos participantes da Oficina de Construção do Programa de Mentoria.

O Programa de Mentoria ficou sob a responsabilidade da Comissão de Assuntos Estudantis (CAE), que coordenou os recursos institucionais para desenvolver, supervisionar e promover as ações necessárias para o início do programa. No ano de 2020, foi ofertado para estudantes ingressantes nos cursos de graduação em Enfermagem e Medicina.

\section{Atividades}

\section{Estratégia de acesso e capacitação de mentores}

Em fevereiro de 2020, foi realizada a Oficina Inaugural para Mentores que apresentou a estrutura e o funcionamento das atividades que constituem o Programa de Mentoria. A entrada de mentores ocorreu de forma espontânea após chamado institucional ou por convite elaborado pelo $\mathrm{Gg}$ para profissionais identificados como tendo perfil adequado à proposta. Na oficina, o programa previamente construído foi revisitado, rediscutido e ajustado, buscando a apropriação pelos mentores.

Ao final da oficina, um quadro circular foi construído colocando-se no centro os participantes que se consideravam parte do $\mathrm{Gg}$, na porção intermediária, os mentores, e na parte mais periférica os simpatizantes do programa. Outros professores e profissionais puderam se inscrever a partir de solicitação pessoal.

\section{Divulgação do Programa Mentoria para os mentores e mentorados}

A fim de divulgar a atividade e envolver os alunos, o $\mathrm{Gg}$ apresentou o Programa de Mentoria nos espaços institucionais da congregação e dos conselhos de cursos e de classes. Ressaltou-se que o objetivo do programa era promover a qualidade de vida dos alunos, de modo a desconstruir concepções anteriores direcionadas a estudantes com dificuldades acadêmicas. O Programa Mentoria foi e continua sendo divulgado por meio eletrônico e em reuniões nos diferentes ambientes das instituições: FMB, IBB e Hospital das Clínicas da FMB.

\section{Estratégias de acesso dos mentorados}

O acolhimento dos mentorados teve início, antes da pandemia, por meio de eventos de sensibilização atrelados à Semana de Recepção dos primeiranistas, com o objetivo de apresentar, promover e divulgar o programa. Oficinas e vivências buscaram produzir afinidades entre alunos e o programa, já sinalizando que o convite para acesso seria feito nos próximos meses.

Com o decreto da pandemia e a volta dos alunos para suas famílias e cidades, o programa passou por ajustes, com atraso de quatro meses até seu início efetivo. Nesse período, o Gg conversou com representantes discentes, divulgou vídeos com palavras de acolhimento e se colocou à disposição para conversas individuais, até que o programa pudesse realmente ser oferecido a todos. Definidas as datas de oficinas, enviaramse aos representantes de classes vídeos curtos que ressaltavam os objetivos do programa, divulgavam as datas para oficina e convidavam os estudantes a participar.

\section{Apresentação e formação de grupos entre mentores e mentorados}

A Oficina de Sensibilização inicial para os estudantes ocorreu de forma virtual, buscando ser um ambiente lúdico, leve e acolhedor, em que os mentores pudessem se apresentar e promover a interação entre eles e os mentorados, e a formação de vínculos. 
No início da oficina, a direção da FMB-Unesp apresentou o programa e sua construção coletiva, e convidou os alunos a se envolver voluntariamente, acolhendo e demonstrando afetividade e interesse. Logo após, a coordenadora do programa contou uma etapa da sua biografia, suas dificuldades de adaptação à vida universitária, ressaltando a importância dos professores que a ajudaram a vivenciar essa etapa com mais confiança, alegria e determinação. Em seguida, a apresentação dos mentores foi feita a partir da dinâmica "Quem sou eu?" via padlet, ferramenta on-line/gratuita que possibilita criar quadros em mural, compostos de figuras e escritas construídas coletivamente, de modo a visualizar o processo em curso. A dinâmica foi construída com imagens de objetos escolhidos pelos próprios mentores que pudessem representá-los (Figura 1), sem que os alunos soubessem quem era, com o intuito de instigar o futuro mentorado a desvendar qual objeto correspondia a determinado mentor. Cada mentor foi apresentado também por um aluno mais velho (por vídeo), descrevendo o seu perfil, e dando dicas para que os mentorados desvendassem qual objeto pertencia ao mentor. Os alunos inseriram suas hipóteses sob a mediação da pedagoga do NAP.

Apresentaram-se as plataformas utilizadas pelo programa (Instagram e Moodle), convidando os alunos a acessar para mais informações sobre os mentores. Foi dado prazo para que cada aluno declarasse as preferências entre os mentores utilizando

Figura 1. Exemplo de imagens dos objetos selecionados pelos mentores para a dinâmica "Quem sou eu?", realizada durante a Oficina de Sensibilização para os primeiranistas do curso de graduação em Enfermagem e Medicina - FMB, 2020.

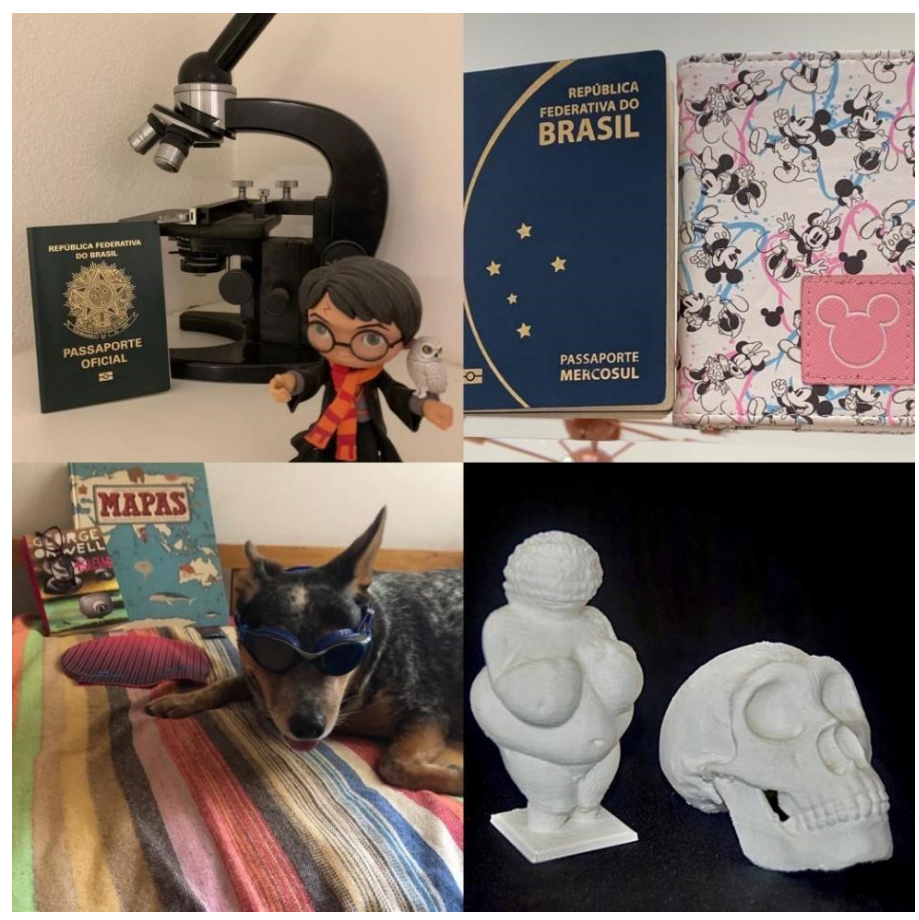

o Google Forms. Após esclarecidas as dúvidas, a oficina foi encerrada com a construção de uma nuvem de palavras: devolutiva dos participantes avaliando a oficina.

$\mathrm{Na}$ formação dos grupos, o Gg observou a preferência de cada aluno, atentou-se à quantidade de mentorados por mentor e reorganizou e reconduziu a entrada de novos integrantes entre os grupos já formados.

A adesão dos alunos de Enfermagem e Medicina foi de $100 \%$ e $85 \%$, respectivamente. A participação dos estudantes no programa foi voluntária e registrada como atividade complementar, apresentada como ação articulada com os cursos, possibilitando autonomia, aprofundamento, interdisciplinaridade e protagonismo estudantil, e valorizando o crescimento pessoal e profissional do estudante. Na Medicina, a carga horária dessa atividade será incorporada, por estar prevista no projeto pedagógico recentemente reestruturado.

\section{Desenvolvimento do Programa de Mentoria}

- Grupo gestor: A composição do $\mathrm{Gg}$ se deu voluntariamente por pessoas com maior envolvimento e disponibilidade para coordenar ações necessárias para sua realização e tem na CAE sua morada institucional. $\mathrm{O} \mathrm{Gg}$ se reúne uma vez ao mês, avalia o processo em curso, constrói agenda, disponibiliza temáticas e metodologias para os encontros, identifica necessidades específicas de apoio ao mentor, além de outras iniciativas que fortaleçam o ambiente colaborativo e afetivo entre participantes do programa.

- Mentor-mentorados: Cada mentor agenda e realiza as reuniões com seus mentorados, ao menos mensalmente, com duração de uma hora a uma hora e meia, com compartilhamento de experiências positivas ou desafiadoras, discussão de temas escolhidos ou atividades lúdicas com o intuito de fortalecer as relações no grupo. Os mentores escolhem livremente o formato das reuniões: rodas de conversa, oficinas e jogos. Ao identificar os temas de interesse dos mentorados, o mentor pode abordálos ou convidar outros colegas, buscando ampliar os olhares e desenvolver a capacidade crítica dos alunos. Alguns temas foram comuns ao longo desse ano de mentoria, como gestão do tempo, saúde mental, iniciação científica e extensão universitária (Quadro 2). São notáveis o comprometimento dos mentores, os esforços realizados e as formas criativas e colaborativas encontradas para o melhor desempenho do papel. 
Quadro 2. Conteúdos sugeridos nos encontros entre mentores e mentorados, construídos durante reunião com grupo gestor do Programa de Mentoria da FMB - Botucatu/SP.

\section{Proposta de mentoria da FMB}

Universidade: ingresso e papel social

Orientação acadêmica

Estratégias de comunicação

Acolhimento e vínculo

Relações interpessoais
Definição do papel e da função do mentor. Características necessárias para o desempenho do papel de mentor. Distinção da função do mentor em relação aos outros papéis implicados na vida do mentorado (pais/amigos/profissionais de saúde e da educação).

O contexto do estudante de hoje: sua realidade e fatores socioculturais. Papel social da universidade na promoção da diversidade. Políticas e estratégias de permanência estudantil. Engajamento estudantil.

Planejamento do tempo/autogestão do tempo. Auxiliar nas dúvidas referentes ao percurso acadêmico, envolvendo a pluralidade de atividades e opções

Dimensões verbais e não verbais; estratégias verbais para abordagem acolhedora; iatrogenias da comunicação; escuta; sensibilidade; diálogo (considerando o contexto e a história de vida do mentorado); espaço de encontro; linguagem clara, objetiva e acessível. Comunicação não violenta.

Conceito que envolve duas dimensões: a) presença implicada - acolher, reconhecer e interpelar; b) presença reservada - dar tempo e espaço, esperar, manter-se disponível sem intromissões excessivas. Validar as experiências do outro; ampliação do olhar sobre o outro.

Horizontalidade das relações; evitar a predominância do poder e domínio no exercício da mentoria. Estabelecer compromisso (negociação e pactuação); corresponsabilidade. Trabalho em grupo.

Fonte: Elaborado pelos participantes da Oficina de Construção do Programa de Mentoria.

Quadro 3. Percepções dos alunos acerca do Programa de Mentoria da FMB coletadas a partir de um questionário enviado aos participantes do programa, 2020.

“Uma relação de amizade, com muito aprendizado e troca de experiências, além de ser uma fonte de apoio/suporte."

"Uma oportunidade de amadurecer dentro da faculdade a partir do compartilhamento de conhecimento e experiências."

"Ser amigo e irmão mais novo de alguém admirável."

"Orientação, inspiração e direcionamento."

"Uma ação colaborativa em que o mentor oferece ao mentorado sua experiência com a vivência acadêmica, mas de uma forma diferente da que poderia ser encontrada em livros ou em outros alunos, um tipo de experiência que só o docente tem por sua atuação."

“Parceria. Relação em que poderei aprender tanto profissionalmente, quanto pessoalmente. Acredito que com a mentoria absorverei e terei muitas experiências construtivas e, se tudo der certo, fazer uma nova e boa amizade que levarei sempre, ainda que apenas em lembranças, para o resto de minha vida."

Fonte: Trechos retirados do formulário de avaliação do programa preenchidos pelos alunos participantes por meio de Google Forms.

O vínculo criado entre mentor e mentorados favorece um ambiente de troca e discussão dos desafios que a instituição vive neste momento de pandemia, o que colabora para um olhar crítico e empático em relação às formas de gestão em tempos de distanciamento social e valoriza o protagonismo e a qualidade do processo de aprendizagem sem perder de vista a segurança dos envolvidos.

O Quadro 3 mostra as percepções dos mentorados acerca do programa.

- Mentores e grupo gestor: O Gg se reuniu com os mentores bimestralmente. O compartilhamento de vivências, dificuldades e superações ocupa espaço privilegiado nas discussões. Nesses momentos, os mentores trocam experiências, estratégias, formas de lidar com desafios e ideias criativas para tornar o encontro mais leve e dinâmico e criar vínculo, além de compartilharem temas de maior interesse dos alunos. Ao identificar necessidades de capacitação, o Gg organiza discussões e sempre que necessário busca apoio em serviços como o Seapes ou do Departamento de Neurologia, Psicologia e Psiquiatria que apoiam, orientam e capacitam os mentores para exercer essa função.

- Lembranças afetivas oferecidas pelo programa: No contexto da pandemia, dentro de um ambiente de relação institucional em que o meio virtual é o 
contato principal entre alunos e instituição, o Gg e os mentores do programa optaram por enviar aos alunos, por correio, uma lembrança de Natal. Como foi considerado simbólico e importante que essa lembrança fosse fisicamente palpável, ela foi enviada às casas dos alunos. Cada lembrança tinha um cartão com a nuvem de palavras construída pelos alunos na oficina Inaugural, um tirante de crachá com o escrito da MentoRIA e uma mochila personalizada com o logo institucional (Figura 2A). Em fevereiro de 2021, houve retorno de curta duração dos primeiranistas às atividades práticas presenciais, cumprindo os protocolos sanitários e o rastreamento do novo coronavírus da síndrome respiratória aguda grave 2 (severe acute respiratory syndrome coronavirus 2 - Sars-CoV-2) em todos estudantes. Foram recebidos por gestores do programa e mentores de grupos, em ambiente aberto, com acolhimento, estimulando o registro

Figura 2. Kits elaborados pelos mentores e pelo grupo gestor do programa para os mentorados. (A) Kit enviado por correio aos alunos no Natal de 2020. (B) Kit entregue aos alunos presencialmente no momento de acolhimento para atividades práticas na FMB, em fevereiro de 2021. (C) Árvore de desejos construída pelos alunos a partir da pergunta: "O que desejo para 2021?" no momento de acolhimento para atividades práticas na FMB, em fevereiro de 2021.

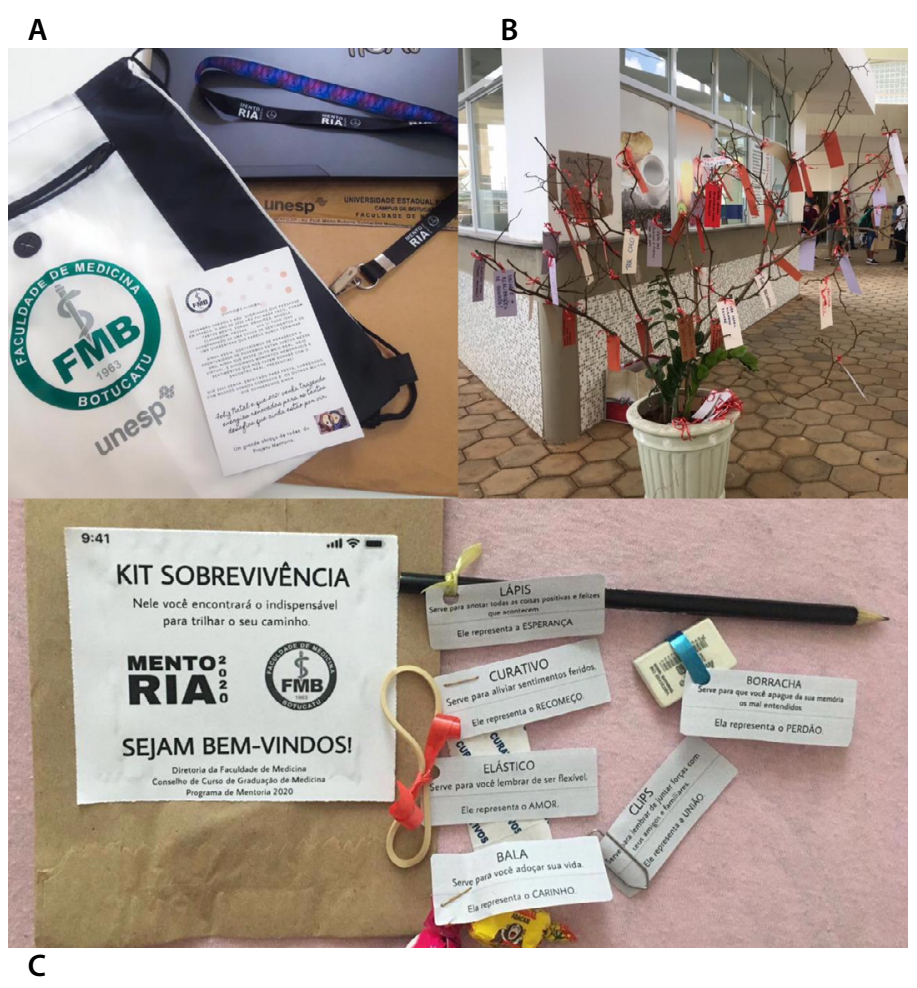

de sensações na "Árvore de desejos" (Figura 2C) a partir da pergunta "O que desejo para 2021?"; também receberam o kit "Sobrevivência" (Figura 2B), trazendo novamente concretude e afetividade para a relação deles com a instituição.

\section{DISCUSSÃO}

Proposta de mentoria, seleção e apoio aos mentores

A construção coletiva do Programa de Mentoria, mediada pela qualidade da assessoria externa, trouxe diversidade de discussões e vivências que aguçaram a criatividade e estimularam o vínculo e a apropriação dos princípios norteadores do programa pelos diferentes participantes do processo. O programa foi estruturado para início em 2020, e a pandemia trouxe mais clareza da sua importância para a instituição, os mentores e os mentorados. $\mathrm{O}$ atraso de quatro meses na implantação não foi observado como prejudicial, já que os professores e profissionais envolvidos nas diferentes estratégias e adaptações necessárias naquele momento de transição eram, muitas vezes, os mesmos participantes do Programa de Mentoria, e a sobrecarga das atividades precisava ser reconhecida e aceita.

A construção coletiva do programa, que envolveu, desde os primórdios, pessoas de diversos locais da faculdade, e a divulgação da atividade nos diferentes órgãos administrativos da instituição - conselhos de classe e de cursos, congregação, departamentos e chefias - deram visibilidade ao programa e possibilitaram que os profissionais interessados fossem identificados e se voluntariassem. Essa estratégia foi de fundamental importância para a adesão de mentores e pode auxiliar na ampliação do programa para os outros anos de graduação. Além do chamado institucional a docentes e profissionais médicos e enfermeiros da FMB, o Gg também fez contatos com indivíduos reconhecidos como portadores das características desejáveis ao mentor: interesse, empatia, abertura para diálogo e capacidade de construir vínculo3 ${ }^{3}$ o que possibilitou diversas formas de acesso dos interessados ao programa.

Entre os mentores, foi possível observar a satisfação de fazer parte de um momento importante da vida dos alunos, o que fortaleceu o papel do professor e a experiência dele, e contribuiu, num momento tão ímpar da humanidade, para o desenvolvimento do seu grupo de mentorados. Mas ainda não se encontraram meios na FMB para que a atividade de mentor fosse reconhecida ou valorizada dentro da carreira docente, nem remunerada, como em outros programas ${ }^{5}$.

A escolha da oficina como uma das dinâmicas do processo de envolvimento de mentores foi importante para reconhecer as expectativas e necessidades que emergiram do 
grupo de mentores e possibilitar a apropriação dos objetivos do programa por eles. Sheri et al. ${ }^{6}$ reforçam a importância dos programas de treinamento de mentores para o bom desenvolvimento dos mentorados nas competências relacionais e clínicas. Ao final, a dinâmica dos círculos de pertencimento possibilitou que cada participante da oficina pudesse visualizar e compartilhar com o grupo o seu nível de envolvimento com o programa no momento e sua disponibilidade.

É importante ressaltar que um princípio fundamental que norteia a mentoria é o modo como as relações se estabelecem. Pereira et al. ${ }^{7}$, ao discutirem os problemas do modelo tradicional na educação médica, exploram o quanto ele reforça a ideia de relações hierárquicas, assimétricas e distantes entre professor e aluno. As relações hierárquicas e distantes influenciam a formação dos profissionais e muito provavelmente se reproduzem nos consultórios e hospitais em que esses médicos atuam. Quando se acolhem os mentores e se estabelecem espaços que propiciam a empatia e a solidariedade, há a expectativa de que a experiência interfira nas vivências entre mentores e mentorados.

É necessário trabalhar na criação do manual do mentor, em que sejam veiculadas informações importantes como aspectos gerais do Programa de Mentoria, objetivos e diretrizes do programa, composição do $\mathrm{Gg}$ e instâncias institucionais de apoio ao estudante da FMB-Unesp, Comissão de Assuntos Estudantis (CAE), Coordenadoria de Permanência Estudantil (Cope), Seapes e conselhos de classe e de cursos), de modo a fortalecer a base comum de princípios que compõe o programa.

\section{Desenvolvimento da mentoria entre mentores e mentorados}

As reuniões mensais entre mentor e mentorados se fortaleceram como espaço de troca, construção de vínculo, permitindo uma dinâmica de interação ágil e possibilitando ao mentor mobilizar as competências para que o aluno fosse atendido em suas necessidades. Alguns mentores realizaram mais de uma reunião por mês, pois achavam necessário e tinham disponibilidade. Sempre que preciso, quando as demandas extrapolavam o limite da relação pedagógica proposta pela mentoria, foram acionadas as redes de apoio, formal e informal, ao aluno. Esse apoio tem sido fundamental para que o mentor se sinta apoiado em diferentes aspectos.

A rede de apoio na instituição é composta por diferentes comissões ou serviços com interesse especial em proporcionar apoio aos alunos (Seapes, NAP, CPE, CAE), assim como profissionais da área de psiquiatria e psicologia do Departamento de Neurologia e Psiquiatria da FMB-Unesp. A rede informal é, por sua vez, composta por vínculos do aluno com a família, os amigos e as pessoas da comunidade, tendo como características a familiaridade e a proximidade, com envolvimento afetivo ${ }^{8}$.

Os temas trazidos pelos alunos chamam a atenção para a importância de maior discussão e capacitação nas relações interpessoais, na comunicação e na saúde mental, temas pouco presentes no currículo formal para os primeiranistas. $\mathrm{O}$ contexto da pandemia parece ter influenciado o surgimento prioritário desses temas, que, com o profissionalismo e as curiosidades em relação à profissão, têm sido relatados como os mais comumente citados pelos alunos ${ }^{9}$.

Os mentores identificaram que o contato sistemático com o grupo é fundamental, mas necessidades especíicas somente foram identificadas quando havia contato direto individual, possivelmente por constrangimento, timidez, alto nível de exigência pessoal, características culturais, familiares ou individuais. Alguns programas apresentam uma proposta de mentoria mais personalizada, um mentor para cada aluno, colaborando para a percepção dos mentores da necessidade do contato individual para que possam ter uma visão melhor de necessidades individuais ${ }^{5}$. Poder compartilhar com os outros mentores essas impressões certamente contribui para a melhor qualidade do programa.

Moreira et al. ${ }^{9}$ apresentaram as estratégias utilizadas por um programa de mentoria no contexto da pandemia, incluindo atividades virtuais com discussão de filmes e apadrinhamento de crianças em situação de vulnerabilidade na cidade natal dos mentorados, mostrando a importância da criatividade nas estratégias na mentoria.

O grupo de mentores era composto apenas por professores e profissionais da instituição. Outras experiências avaliam positivamente a participação de alunos mais graduados como comentores, de modo a construir pontes entre professores mentores e seus mentorados, e facilitar e fortalecer vínculos ${ }^{10}$.

A interação entre diferentes grupos de mentoria possibilitaria uma atuação menos solitária dos mentores, com apoio mútuo, maior troca e ampliação da rede de referências dos estudantes. Eventos abertos a todos os mentores e mentorados com a presença de especialistas poderiam abordar temáticas de interesse amplo. Há de se cuidar para que esses eventos não substituam nem enfraqueçam o vínculo mentor-mentorado, foco principal do programa. Uma mostra anual do Programa de Mentoria possibilitaria trocar aprendizados construídos nos grupos, conhecer formas diferentes de interagir e criar vínculos. Trocas entre instituições poderiam fortalecer os grupos locais e contribuir para uma análise crítica e construção de novos caminhos para os programas de mentoria em tempos de pandemia.

Com a ampliação da cobertura do programa nos 
diferentes anos da graduação em Enfermagem e Medicina, espera-se contribuir para o uso assertivo das oportunidades acadêmicas oferecidas pela FMB-Unesp, favorecendo o desenvolvimento humano e da identidade profissional.

\section{Avaliação do programa}

Apesar de ser um programa de início recente, na sua construção já se planejava um processo de acompanhamento avaliativo formativo desde a implantação, buscando o desenvolvimento contínuo e a detecção de pontos a serem aprimorados.

Diante da complexidade do conjunto de qualidades esperadas para o mentor e do papel central no mentor para o desenvolvimento do programa, considera-se fundamental que a atividade do mentor esteja em processo contínuo de aprimoramento e avaliação. A educação permanente do mentor é uma das dimensões fundamentais do Programa de Mentoria. Acredita-se que os encontros bimestrais entre o $\mathrm{Gg}$ e os mentores são um espaço para que as temáticas relevantes possam ser desenvolvidas, valorizando a aprendizagem entre pares num espaço aberto de troca e construção coletiva, por meio de discussões de situações enfrentadas e encontro com especialistas. Quando cada mentor relata a atividade desenvolvida, a periodicidade de encontros, as metodologias utilizadas e as dificuldades enfrentadas, o $\mathrm{Gg}$ avalia subjetivamente como está sendo construída a relação entre mentor e mentorados, e identifica formas de auxiliar os mentores, mas reconhece-se que essa é uma ferramenta frágil. Kalén et al. ${ }^{5}$ utilizaram questionários estruturados para investigar as experiências e percepções dos alunos com um programa de mentoria na Suécia, o que possibilitou avaliar a atividade do mentor e identificar barreiras para o sucesso do programa.

Martins et al. ${ }^{3}$ descreveram o uso de metodologias qualitativas de pesquisa na investigação das vivências dos estudantes na mentoria, demonstrando a riqueza de sentimentos e percepções que essa ferramenta é capaz de identificar. Em nosso programa, foi possível coletar a experiência dos mentorados em relação ao programa por meio de questionário, mas novos olhares precisam ser avaliados e de forma contínua.

Assim como a atuação dos mentores, a condução do programa pelo Gg também precisa ser avaliada, especialmente com base no olhar deles. Estratégias de devolutivas estruturadas em formato de feedbacks dos mentores em relação ao $\mathrm{Gg}$ podem fortalecer o grupo e criar uma cultura avaliativa na instituição e no programa.

\section{CONCLUSÃO}

Em tempos de pandemia da Covid-19, quando os primeiranistas não puderam vivenciar a vida universitária na instituição, passando o ano praticamente em ensino remoto, o Programa de Mentoria ganhou especial importância ao fortalecer o sentimento de pertencimento dos alunos à instituição e criar um ambiente de afetividade e vínculo.

O programa, por meio dos mentores, permite novas formas de valorizar diversas vertentes do engajamento estudantil, identificar necessidades individuais e exercer o papel social da universidade na promoção da diversidade, oportunizando o conhecimento sobre as políticas públicas e estratégias de permanência estudantil.

Para que se possam atingir os objetivos do programa, é fundamental o fortalecimento do vínculo entre $\mathrm{Gg}$ e mentores, o que significa criar um ambiente de educação permanente com diversidade, trocas e aprendizado mútuo. Quando os mentores se sentem apoiados e ouvidos, estão mais preparados para apoiar e ouvir seus mentorados.

O apoio institucional tem sido fundamental desde a implantação até o desenvolvimento. O auxílio técnico administrativo possibilita a viabilização de propostas e a efetiva comunicação entre os diferentes participantes do programa e os conselhos gestores da instituição. O programa conseguiu ter visibilidade entre alunos, professores e profissionais, e está conseguindo se firmar como estratégia para resgatar a afetividade e humanizar as relações entre alunos, professores e instituição, num momento de tantas inseguranças, sofrimentos e desafios.

\section{AGRADECIMENTOS}

Agradecemos a todos os mentores do programa: Adriana Polachini do Valle, Denise Fecchio, Doralina Guimarães Brum Souza, Elenice Bertanha, Fernanda Bono Fukushima, Flávia Helena Pereira Padovani, Luciana Montes de Oliveira, Luciane Alarcão Dias-Melício, Maria Helena Borgatto, Marcos Ferreira Minicucci, Maria Solange de Castro Ferreira, Marli Terezinha C. Duarte, Walnei Fernandes Barbosa e Wellerson Rodrigo Scarano. Agradecemos também ao NAP, nas pessoas de Denise Zornoff e Marcelo Henrique do Carmo Balestrin, ao especializando Everton de Oliveira Santana Júnior, à estagiária Beatriz Fernanda Gonçalves e à secretária da $\mathrm{CAE}$, Jordana Revoredo Chaves.

\section{CONTRIBUIÇÃO DOS AUTORES}

Todos os autores participaram da experiência e da construção do texto.

\section{CONFLITO DE INTERESSES}

Declaramos não haver conflito de interesses.

\section{FINANCIAMENTO}

Declaramos não haver financiamento. 


\section{REFERÊNCIAS}

1. Dyrbye LN, Thomas MR, Shanafelt TD. Medical student distress: causes, consequences, and proposed solutions. Mayo Clin Proc. 2005;80:1613-22.

2. Graner KM, Cerqueira ATAR. Revisão integrativa: sofrimento psíquico em estudantes universitários e fatores associados. Cien Saude Colet. 2019;24(4):1327-46.

3. Martins AF, Bellodi PL. Mentoring in medical students: a humane and developmental experience. Interface (Botucatu). 2016;20(58):715-26.

4. Guse J, Heinen I, Kurre J, Mohr S, Bergelt C. Perception of the study and mental burden during the COVID-19 pandemic among undergraduate medical students with and without mentoring. GMS J Med Educ. 2020;37(7).

5. Kalén S, Stenfors-Hayes T, Hylin U, Larm MF, Hindbeck H, Ponzer S. Mentoring medical students during clínical courses: a way to enhance professional development. Med Teach. 2010;32(8):315-21.
6. Sheri K, Joan JY, Chuah SEL, Toh YP, Mason S, Krishna LKR. A scoping review of mentor training programs in medicine between 1990 and 2017. Med Educ Online. 2017;24

7. Pereira OP, Almeida TMC. A formação médica segundo uma pedagogia de resistência. Interface (Botucatu). 2005;9(16):69-79.

8. Rosa TEC, Benicio MHD. As redes sociais e de apoio: o conviver e a sua influência sobre a saúde. BIS, Bol Inst Saúde. 2009;(47): 80-3.

9. Moreira SNT, Albuquerque ICS, Pinto Junior FEL, Gomes AHB. Programa de Mentoria do curso de Medicina da Universidade Federal do Rio Grande do Norte: atividades integrativas em foco. Rev Bras Educ Med. 2020;44(4):1-6.

10. Ng YX, Koh ZYK, Yap HW, Tay KT, Tan XH, Ong YT, et al. Assessing mentoring: a scoping review of mentoring assessment tools in internal medicine between 1990 and 2019. PLoS One. 2020;15(5). 